\title{
Costimulatory Pathways: Physiology and Potential Therapeutic Manipulation in Systemic Lupus Erythematosus
}

\author{
Nien Yee Kow and Anselm Mak \\ Division of Rheumatology, Department of Medicine, University Medicine Cluster, Yong Loo Lin School of Medicine, \\ National University of Singapore, Level 10, NUHS Tower Block, 1E Kent Ridge Road, Singapore 119228
}

Correspondence should be addressed to Anselm Mak; mdcam@nus.edu.sg

Received 31 May 2013; Accepted 8 July 2013

Academic Editor: Guixiu Shi

Copyright (C) 2013 N. Y. Kow and A. Mak. This is an open access article distributed under the Creative Commons Attribution License, which permits unrestricted use, distribution, and reproduction in any medium, provided the original work is properly cited.

\begin{abstract}
System lupus erythematosus (SLE) is an immune-complex-mediated autoimmune condition with protean immunological and clinical manifestation. While SLE has classically been advocated as a B-cell or T-cell disease, it is unlikely that a particular cell type is more pathologically predominant than the others. Indeed, SLE is characterized by an orchestrated interplay amongst different types of immunopathologically important cells participating in both innate and adaptive immunity including the dendritic cells, macrophages, neutrophils and lymphocytes, as well as traditional nonimmune cells such as endothelial, epithelial, and renal tubular cells. Amongst the antigen-presenting cells and lymphocytes, and between lymphocytes, the costimulatory pathways which involve mutual exchange of information and signalling play an essential role in initiating, perpetuating, and, eventually, attenuating the proinflammatory immune response. In this review, advances in the knowledge of established costimulatory pathways such as CD28/CTLA-4-CD80/86, ICOS-B7RP1, CD70-CD27, OX40-OX40L, and CD137-CD137L as well as their potential roles involved in the pathophysiology of SLE will be discussed. Attempts to target these costimulatory pathways therapeutically will pave more potential treatment avenues for patients with SLE. Preliminary laboratory and clinical evidence of the potential therapeutic value of manipulating these costimulatory pathways in SLE will also be discussed in this review.
\end{abstract}

\section{Introduction}

Systemic lupus erythematosus (SLE) is an autoimmune condition in which autoantibodies against various nuclear and nonnuclear antigens trigger immune-complex-mediated inflammation that can result in organ damage [1]. Similar to other inflammatory and autoimmune conditions, the pathogenic processes that contributed to SLE involve complex interactions between immunocytes and nonimmunocytes such as endothelial and epithelial cells through a number of receptor-ligand systems [2]. Such receptorligand association is crucial in initiating and regulating both innate and adapted immunity, from initial presentation of danger signals to naïve immunocytes by professional antigenpresenting cells (APCs) to the moment when communication between $\mathrm{T}$ and $\mathrm{B}$ cells is driven by specific antigenic epitopes. The cognate T-B-cell interactions which lead to T-celldependent autoantibody production by the $\mathrm{B}$ cells are central to the pathogenesis of SLE [3].
Generally, antigen presentation is broadly divided into four stages: adhesion, antigen-specific activation, costimulation, and cytokine production and signalling [4]. Instead of initiating cell activation, the process of adhesion which occurs between cells, as well as between cells and extracellular matrix that requires adhesion molecules such as integrins and selectins, is essential in bridging the cells together before subsequent cellular activation takes place [5]. After physically approximating immunologically important APCs and lymphocytes, the APCs capture, internally process, and present peptides of antigen-specific sequences to $\mathrm{T}$ lymphocytes through interaction between the major histocompatibility complex (MHC) of the APCs and T-cell receptors (TCRs) on the T cells in an antigen-specific manner. The binding and interaction between the MHC and TCR are, however, insufficient to propagate and sustain downstream proinflammatory signals. Additional intercellular signals in the form of costimulatory pathways are required to perpetuate the ensuing proinflammatory pathways [6]. At this stage, communication 
between the cells involved through costimulatory signals is critical in determining if such cell-cell association ensues and terminates. Indeed, besides perpetuating proinflammatory signals, costimulatory pathways are also crucial in attenuating the active immune system or generating peripheral immune tolerance for avoiding unnecessary tissue damage incurred by the overwhelmingly active proinflammatory effector signals [7]. In the subsequent sections, a brief overview of the physiology of well-characterized costimulatory molecules will be highlighted, followed by a discussion of the relevance of some pathophysiologically important costimulatory pathways operant in SLE. Emerging data regarding the therapeutic potential of costimulatory molecule blockades on laboratory benches and randomized controlled clinical trials will also be discussed.

\section{An Overview of Costimulatory Molecules and Their Signalling Pathways}

2.1. CD80/86-CD28 and ICOS-B7RP1. Costimulatory molecules are broadly divided into those belong to the immunoglobulin (Ig) superfamily (IgSF) and the tumour necrosis factor (TNF) superfamily (TNFSF) based on their phenotypic and signalling features. The CD28 and CD80 (B71)/CD86(B7-2) represent one of the most relevant costimulatory pathways of the Ig family. During the very early stage of T-cell activation, CD28 is expressed on T cells and is ligated by CD80/CD86 which are constitutively expressed on dendritic cells (DCs) and inducible in other professional APCs such as B cells and monocytes. CD28 stimulation has been shown to prolong and augment IL-2 production from $\mathrm{T}$ cells and prevent the development of peripheral immune tolerance [8]. Consequently, the stimulated $\mathrm{T}$ cells further mature, differentiate, and signal the B cells to proliferate and differentiate into antibody-producing plasma cells for production of antibodies. More costimulatory pathways are further activated subsequently to enhance the cognate interactions between APCs and T lymphocytes and intensify the proinflammatory effector signals.

Another recently identified costimulatory system of the same group as $\mathrm{CD} 28-\mathrm{CD} 80 / 86$ is the inducible costimulator (ICOS)-B7-related protein 1 (B7RP1) pathway. The ICOS which shares similar structural and functional similarities as CD28 was characterized in 1999 [9, 10]. Structurally, ICOS is similar to CD28 in that it is also a transmembrane glycoprotein which is expressed on activated T cells. Functionally, on binding with its ligand B7RP1 which is constitutively expressed on B cells and inducible on monocytes and DC $[9,10]$, ICOS triggers germinal centre formulation, clonal expansion of $\mathrm{T}$ cell, $\mathrm{T}$-cell-dependent antibody production, and isotype switching of B cells [10]. ICOS has been found to be highly expressed on activated CD4+ T cells in patients with autoimmune conditions such as rheumatoid arthritis (RA), SLE, and inflammatory bowel disease [11-13]. On the other hand, ICOS deficiency is found in patients with primary immunodeficiency, with impaired CD4 and CD8 effector functions and reduced memory T-cell population, together with features of common variable immunodeficiency characterized by hypogammaglobulinemia and recurrent bacterial infection [14].

2.2. CD70-CD27. After initial activation of $\mathrm{T}$ cells is achieved via MHC-TCR and CD80/86-CD28 interactions, CD70 (TNFSF7) starts to be expressed on the activated T cells and its cognate association with CD27, which is expressed on B and natural killer (NK) cells, serves to strengthen the costimulatory signals between the immunocytes [15]. Activation of CD70 enhances T-cell-dependent antibody production by promoting germinal center formation, B-cell activation, and clonal expansion, as well as differentiation into plasma cells [16]. In the T-cell compartment, cognate interaction between $\mathrm{CD} 70$ and $\mathrm{CD} 27$ also induces the proliferation of and cytokine secretion by CD4+ and CD8+ T cells and development of cytotoxic T-cell responses by CD8+ T cells [17].

2.3. CD40-CD40L. CD40 belongs to the TNFSF (TNFSF5) and is expressed on APCs, B cells, and traditional nonimmune cells such as endothelial, epithelial, and renal tubular cells [18]. On activation upon ligation with CD40L expressed on activated $\mathrm{T}$ cells, CD40 can deliver even stronger activation signals than that of surface bound Ig to B cells. Activated $\mathrm{T}$ cells transiently express the CD40L which interacts with CD40 on B cells and further drives B-cell differentiation, maturation, and isotype switching, especially those in the germinal centers [19]. In addition, signal transduction through CD40 upregulates the expression of CD80/CD86 which further intensifies costimulatory signals to the T cells involved in the interaction [20]. Overexpression of CD40L on T cells has been found in a number of autoimmune diseases which are characterized by overproduction of autoantibodies [21, 22]. On the other hand, deficiency of CD40L, such as in patients with CD40 gene mutation, would lead to Ig class-switch recombination deficiency characterized by high IgM but low IgA and IgG levels and recurrent opportunistic infection [23].

During the later stage of T-cell activation, other costimulatory molecules which belong to the TNFRSF such as CD137 and OX40 start to participate in the scene of costimulation. These molecules are only expressed on the activated $\mathrm{T}$ cells during the later stage of activation. Expressions of these costimulation molecules are required for further sustaining differentiation of the activated T cells, with an aim to prolong their survival and perform specific effector and memory functions [24].

2.4. CD137-CD137L. CD137 belongs to TNFSF9, and it is a potent costimulatory receptor molecule which is mainly expressed on stimulated $\mathrm{T}$ cells and NKT cells [25]. In DCs and CD4+ CD25+ Foxp3+ Treg cells, CD137 is expressed in a constitutive manner and around 48 hours after initial stimulation, CD137 is predominantly expressed on CD4+ and CD8+ T cells $[26,27]$. In both murine system and humans, cognate interaction between CD137 and CD137L on activated $\mathrm{T}$ cells and $\mathrm{B}$ cells, respectively, leads to proliferation and differentiation of both interacting cells and results in 
substantial Ig production, before apoptosis of B cells or APCs that occurs upon prolonged stimulation at the terminal stage of immune activation [28]. Indeed, bidirectional signalling ensues in the T and B cells or APCs during CD137-CD137L interaction. Such mutual signalling leads to initial stimulation of both communicating cells followed by their apoptosis, suggesting that $\mathrm{CD} 137$ ligation acts as an initial checkpoint to attenuate the over-active proinflammatory effector response [28].

2.5. OX40-OX40L. OX40 (CD134) belongs to the TNFSF4. Similar to CD137, OX40 is expressed on activated CD45RO+ CD4+ T lymphocytes [29]. Signalling of OX40 requires and is controlled by its ligand, OX40L (CD134L), which is constitutively expressed on APCs including B cells, macrophages, DC, and endothelial cells [30]. While OX40 signalling enhances survival of $\mathrm{T}$ cells and their subsequent cytokine production and expansion of their memory cell pool, stimulation of OX40L enhances B-cell proliferation and differentiation [31]. A recent study has found that OX40L stimulation inhibited the generation of IL-10-producing CD4+ Tregs cells from memory and naive $\mathrm{T}$ cells. In addition, OX40L ligation inhibited IL-10 production and suppressive function of differentiated type 1 regulatory CD4+ T cells (Tr1) [32].

2.6. Downregulation of Proinflammatory Signals during the Late Stage of T-Cell Activation. Costimulation cannot continue unchecked or else overwhelming proinflammatory response will ultimately ruin the host. The costimulatory system consists of peculiar mechanisms which can dampen the proinflammatory signals, achieve immune homeostasis, and assist in the development of peripheral tolerance. CTLA4 (CD152), a homolog of CD28, starts to be expressed on activated $\mathrm{T}$ cell and binds to CD80/86 when T-cell activation has reached its peak [33]. Indeed, the affinity between CTLA4 and CD80/86 is much higher than that between CD28 and CD80/86 [34, 35]. CTLA-4 activation signals the T cells to attenuate its proliferation and proinflammatory effector signals [36]. Once the CTLA-4 is upregulated, expression of CD28 on T cells will start to be downregulated by endocytosis [36]. Apart from CTLA-4, prolonged interaction between CD137 and CD137L leads to apoptosis of the participating cells which also results in attenuation of the proinflammatory signals [28]. One of the mechanisms postulated is that prolonged activation through CD137 signalling induces large amount of IFN $\gamma$ production by CD8 $+\mathrm{T}$ cells, which in turn stimulates apoptosis of B cells and DCs and results in downregulation of Ig production and CD80/86 expression respectively. Downregulated B7 expression in DCs further weakens the communication with $\mathrm{T}$ cells and attenuates the costimulatory signals [28].

2.7. Intracellular Signalling Pathways of Costimulatory Molecules. While a number of downstream signalling pathways after stimulation of costimulatory molecules have been discovered, the functions of many of these pathways are still not fully understood, not mentioning that there are many signalling pathways which have not been discovered or functionally characterized. Nevertheless, Table 1 summarizes the signal transduction pathways of costimulatory molecules in which their functions have been relatively well characterized. Classification of these costimulatory molecules, cells which they are expressed on, and their physiological functions are also briefly described in Table 1. Figure 1 depicts the expression of costimulatory molecules and their concerted effector actions in relation to different stages of immune activation.

\section{Costimulatory Molecules and SLE}

3.1. CD80/86-CD28 Interaction. Involved in the early stage of T-cell activation, the interaction between CD80/86 and CD28 has been extensively studied amongst various costimulatory molecules in SLE. A number of animal studies attempting to block the CD80/86-CD28 system revealed promising results in terms of amelioration of lupus-related glomerulonephritis, autoantibody production, and class switching, as well as mortality [37, 38]. In a murine lupus model, it has been shown that CTLA4-Ig, a recombinant fusion protein comprising a Fc fragment of human IgG1 which binds either to CD80 or CD86 with a much higher avidity than CD28, contracted the autoreactive B-cell population and reduced autoantibody production and Ig class switching [39]. In clinical studies, CTLA-4Ig (abatacept) has been shown to be able to dampen the interaction between $\mathrm{T}$ and $\mathrm{B}$ lymphocytes, leading to potential amelioration of autoimmune-driven inflammation [40]. While promising efficacy and safety of abatacept have been demonstrated for the treatment of RA [41], the results of two-phase IIb/III clinical trials testing abatacept in SLE are rather disappointing $[42,43]$. In a one-year multicentre, double-blind, placebo-controlled trial of 175 patients with moderately active lupus presenting with arthritis, serositis, and discoid lupus receiving either abatacept $(10 \mathrm{mg} / \mathrm{kg})$ or placebo, no statistically significant difference was found between the 2 groups in the primary (new BILAG A or B flare) and the secondary study endpoints [42]. Nevertheless, in post hoc analyses while only BILAG A flare was taken into account, significantly more patients receiving placebo experienced flares $(54.4 \%)$ than those who received abatacept $(40.7 \%)$. In addition, greatest benefit was seen in patients with arthritis, and improvement of patient-reported outcomes such as sleep disturbance, health-related quality of life, and fatigue was more substantial in the abatacept-treated group [42]. Although more serious adverse events were reported in the abatacept-treated group (19.8\% versus $6.8 \%)$, post hoc analyses did provide evidence that abatacept may confer beneficial effect in severe nonrenal lupus and moderate lupus manifestations [42].

A more recent 52-week phase III clinical trial testing abatacept for its safety and efficacy in 290 patients with ISN/RPS class III or IV lupus nephritis on a background of mycophenolate mofetil and glucocorticoids was published in abstract form [43]. Again disappointingly, no significant difference was found between the treatment and placebo groups in time to achieve complete renal response. However, as in the nonrenal lupus trial [42], post hoc analysis revealed that a modified complete response was higher in 
TABLE 1: Summary of the signalling mechanisms and physiological actions of major co-stimulatory molecules in systemic lupus erythematosus.

\begin{tabular}{|c|c|c|c|c|}
\hline $\begin{array}{l}\text { Costimulation } \\
\text { receptor (ref.) }\end{array}$ & $\begin{array}{l}\text { Costimulation } \\
\text { ligand }\end{array}$ & Family & Cells expressing & $\begin{array}{l}\text { Signaling molecules } \\
\text { involved }\end{array}$ \\
\hline $\begin{array}{l}{ }^{*} \mathrm{CD} 80 \\
{ }^{*} \mathrm{CD} 86\end{array}$ & CD28 & IgSF & $\begin{array}{l}\text { CD80/86: APCs } \\
\text { including monocytes, } \\
\mathrm{M} \phi \text {, and DC } \\
\mathrm{CD} 28 \text { : mainly naive } \\
\mathrm{CD} 4+\text { \& CD }+ \text { T cells } \\
\text { during their initial phase } \\
\text { of activation }\end{array}$ & $\begin{array}{l}\text { CD28: phosphorylation by } \\
\text { Lck and FYN, and ITK } \\
\text { which recruits PI3K and } \\
\text { Grb2 PI3K converts PI to } \\
\text { PIP }_{3} \text { and activates Akt and } \\
\text { subsequently NF- } \kappa \text { B } \\
\text { Grb2 binds to SOS1, } \\
\text { phosphorylates VAV1 } \\
\text { which in turn activates } \\
\text { Racl and JNK }\end{array}$ \\
\hline
\end{tabular}

$[79,80]$
CTLA-4: phosphorylation by Lck, FYN, and RLK, binds to PI3K, SHP-2, and PP2A. PLC $\gamma$, and AKT, and hence proinflammatory effector signals are suppressed
T cells during late stage of activation
CD28-B7

family
ICOS: activated T cells B71RP1: APCs and B cells
ICOS: phosphorylation of ERK, JNK, and p38
Action

CD80/86 are constitutively expressed on APCs and B cells CD80/86 are upregulated by inflammation and stimulation of $\mathrm{T}$ cells, and they provide costimulatory signals to CD28 and CTLA-4 Stimulation of CD28 prolongs and augments IL-2 production from T cells and prevents the development of peripheral immune tolerance

Attenuates further costimulation between communicating immunocytes, dampens proinflammatory signals, and produces anergy. CTLA-4 expression induces CD28 endocytosis on activated T cells

ICOS stimulation induces further activation and clonal expansion of $\mathrm{T}$ cells, germinal centre formation, and T-celldependent antibody formation CD137 enhances proliferation of, and memory as well as cytolytic functions of $\mathrm{T}$ cells.

CD137L: Src tyrosine kinase which activates

CD137

$[82,83]$

CD137L

TNFSF

CD137: activated T cells, MEK1/2, P38 MAPK, NK-T cells CD137L: APCs, B cells

It Inhibits CD4+ response and ameliorates autoimmunity due to IFN $\gamma$ production by $\mathrm{CD} 8+$

\section{T cells} subsequently, and NF- $\kappa \mathrm{B}$ (human). Association with TNFR1 which mediates reverse signalling

CD137L induces myelopoiesis, DC maturation, B-cell stimulation, and T-cell proliferation

CD27 stimulation suppresses Th17 effector function and enhances B-cell activation and Ig production. CD70 signalling may regulate cell cycle of B cells and cytotoxicity of T cells

OX40 signalling increases the longevity of $\mathrm{T}$ cells and subsequent cytokine

OX40: T cells

\begin{tabular}{|c|c|c|}
\hline $\begin{array}{l}{ }^{\dagger} \mathrm{OX} 40 \\
{[85,86]}\end{array}$ & ${ }^{\ddagger} \mathrm{OX} 40 \mathrm{~L}$ & TNFSF \\
\hline
\end{tabular}
production and expansion of memory T-cell population.

OX40L binds to OX40, recruits TRAF $2,3,5$, and induces phosphorylation of OX40L signalling enhances $\mathrm{I} \kappa \mathrm{B} \alpha$, and subsequently NF- $\kappa \mathrm{B}, \mathrm{PI}-3 \mathrm{~K}$, and protein kinase $\mathrm{B}$
B-cell proliferation and differentiation OX40L inhibits the generation of IL-10 producing CD4+ Tregs from naive and memory $\mathrm{T}$ cells 
TABle 1: Continued.

\begin{tabular}{|c|c|c|c|c|c|}
\hline $\begin{array}{l}\text { Costimulation } \\
\text { receptor (ref.) }\end{array}$ & $\begin{array}{l}\text { Costimulation } \\
\text { ligand }\end{array}$ & Family & Cells expressing & $\begin{array}{l}\text { Signaling molecules } \\
\text { involved }\end{array}$ & Action \\
\hline $\begin{array}{l}\text { CD40 } \\
{[87]}\end{array}$ & $€_{\mathrm{CD} 40 \mathrm{~L}}$ & TNFSF & $\begin{array}{l}\text { CD40: B cells } \\
\text { CD40L: T cells }\end{array}$ & $\begin{array}{l}\text { CD40: TRAF } 1 / 2,3 / 5,5,6 \text {, } \\
\text { and induces NF- } \kappa \text { B while } \\
\text { TRAF } 2,2 / 6 \text {, and } 6 \text { induces } \\
\text { p38, Akt and JNK Jak } 3 \text { and } \\
\text { induces STAT5 } \\
\text { phosphorylation }\end{array}$ & $\begin{array}{l}\text { Provides a strong activation } \\
\text { signal to B cells for their } \\
\text { differentiation, proliferation, } \\
\text { and hence germinal centre } \\
\text { development, and Ig response } \\
\text { to T-dependent antigens. } \\
\text { CD } 40 \text { also upregulates } \\
\text { CD80/86 expression and } \\
\text { provides further stimulation } \\
\text { signals to T cells. }\end{array}$ \\
\hline
\end{tabular}

Abbreviations: ref: references; CD: cluster of differentiation; IgSF: immunoglobulin superfamily; APCs: antigen-presenting cells; M $\phi$ : macrophages; DC: dendritic cells; TNFSF: tumour necrosis factor superfamily; Lck: lymphocyte-specific protein tyrosine kinase; FYN: protooncogene tyrosine-protein kinase Fyn; ITK: IL2-inducible T-cell kinase; PI3K: Phosphoinositide 3-kinase; Grb2: Growth factor receptor-bound protein 2; PI: phosphatidylinositol; PIP3: phosphatidylinositol $(3,4,5)$-trisphosphate; Akt: PKB is a serine/threonine protein kinase; NF- $\kappa$ B: nuclear factor-kappa-light-chain-enhancer of activated B cells; Sos: son of sevenless homolog 1; Vavl: protooncogene vav; Rac1: Ras-related C3 botulinum toxin substrate 1; JNK: c-Jun N-terminal kinase; CTLA4: cytotoxic T-lymphocyte-associated protein 4; IL: interleukin; RLK: receptor-like kinase; SHP-2: Src homology region 2 domain-containing phosphatase2; PP2A: Protein phosphatase 2A; PLC $\gamma$ : Phospholipase C $\gamma$; B7RP1: B7 related protein 1; ICOS: inducible co-stimulator; ERK: extracellular-signal-regulated kinases; NK-T: natural killer T cells; MEK1/2: mitogen-activated protein kinase kinase 1/2; MAPK: mitogen-activated protein kinase; TNFR1: TNF receptor 1; IFN $\gamma$ : interferon gamma; TRAF: TNF-receptor-associated factors; IkB: inhibitor of $\kappa \mathrm{B}$; Jac3: Janus kinase 3; and STAT5: signal transducers and activators of transcription 5; Ig: immunoglobulin.

${ }^{*} \mathrm{CD} 80=\mathrm{B} 7-1, \mathrm{CD} 86=\mathrm{B} 7-2 ;{ }^{* *} \mathrm{CD} 70=\mathrm{CD} 27 \mathrm{~L} ;{ }^{\dagger} \mathrm{OX} 40=\mathrm{CD} 134 ;{ }^{\ddagger} \mathrm{OX} 40 \mathrm{~L}=\mathrm{CD} 134 \mathrm{~L} ;$ and ${ }^{€} \mathrm{CD} 40 \mathrm{~L}=\mathrm{CD} 154$.

patients who received abatacept [43]. Repeated analyses of these data by less stringent criteria such as the ALMS and LUNAR response criteria also revealed greater difference in complete response favouring the abatacept-treated groups [44]. A randomized controlled phase II trial (ACCESS) comparing the combination therapy of cyclophosphamide (500 mg intravenous infusion fortnightly for 12 weeks) and abatacept (500-1000 mg at 0, 2, and 4 weeks then monthly for 24 to 48 weeks) versus standard cyclophosphamide (500 mg intravenously infusion fortnightly for 12 weeks) in active lupus nephritis is currently underway [45].

Blockade of CD80 by monoclonal antibody has recently been explored in the treatment of lupus-like disease in a mouse model. In a pristane-induced lupus-like disease mouse model, monoclonal antibody against CD80 was shown to be able to attenuate inflammatory response and severity of lupus-like signs [46].

3.2. CD70/CD27 Interaction. Before discussing the impact of the CD70-CD27 interaction on the pathogenesis of SLE, it is useful to highlight the relationship between DNA methylation and SLE. In general, DNA methylation involves the addition of a methyl group to adenosine or cytosine base of the DNA nucleotides and stably alters gene expression [47]. In the early 1990s, global reduction of DNA methylation by 15$20 \%$ was first identified in lupus T cells [48]. Subsequently, the link between DNA hypomethylation, T-cell autoreactivity, and development of SLE was further supported by the association between low 5-methylcytosine content of DNA in blood and disease activity in patients with SLE [49]. Thus, methylation status of lupus susceptible genes such as those coding CD70 and CD40L may affect the clinical expression of SLE. In an animal model of lupus, CD70 overexpression on splenic CD4+ cells was observed in 16-week-old MRL/lpr mice with established lupus-like disease but not in their 5week-old counterparts prior to disease development. Additionally, CD70 expression was found to correlate with DNA hypomethylation of the CD70 gene in activated CD4+ T cells [50]. The expression of DNA methyltransferase 1 (DNMT1) was found to be significantly lower in the 16-week-old mice than that of the 5-week-old mice, and the low DNMT1 level led to T-cell DNA hypomethylation, CD70 overexpression, and consequently age-dependent development of lupus-like disease in the MRL/lpr mice [50].

In humans, CD4+ $\mathrm{T}$ cells of patients with SLE were also shown to overexpress CD70 when compared to healthy subjects, although CD70 expression on CD4+ T cells has not been found to be consistently correlated with lupus disease activity [51-53]. Nevertheless, overexpression on $\mathrm{T}$ cells in SLE patients was confirmed to be the result of hypomethylation of DNA sequences that flank the CD70 promoter due to reduced expression of DNMT1, which results in failure in downregulating CD70 expression once it is induced by $\mathrm{T}$-cell activation [54]. In a recent study which aimed to unravel the mechanism of DNA hypomethylation of $\mathrm{T}$ lymphocytes in patients with SLE, a transcription factor named regulatory factor X1 (RFX1), which functions to recruit DNMT1 to the promoter region of CD70, was shown to be downregulated in human lupus CD4+ T cells, potentially contributing to CD70 overexpression [55]. CD70 overexpression in SLE has been postulated to intensify B cell costimulation with subsequent increase in autoreactive Ig production [52]. In addition to hypomethylation, posttranscriptional modifications on histone protein also play a role in overexpressing CD70 in lupus T cells [56]. In vitro treatment of lupus CD4+ T cells with a histone deacetylase inhibitor was demonstrated to overexpress CD70 in these cells by aberrant histone modifications (increase in $\mathrm{H} 3$ and 


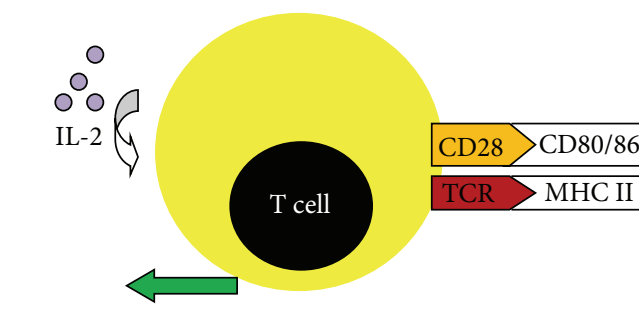

Proliferation and differentiation

(a)

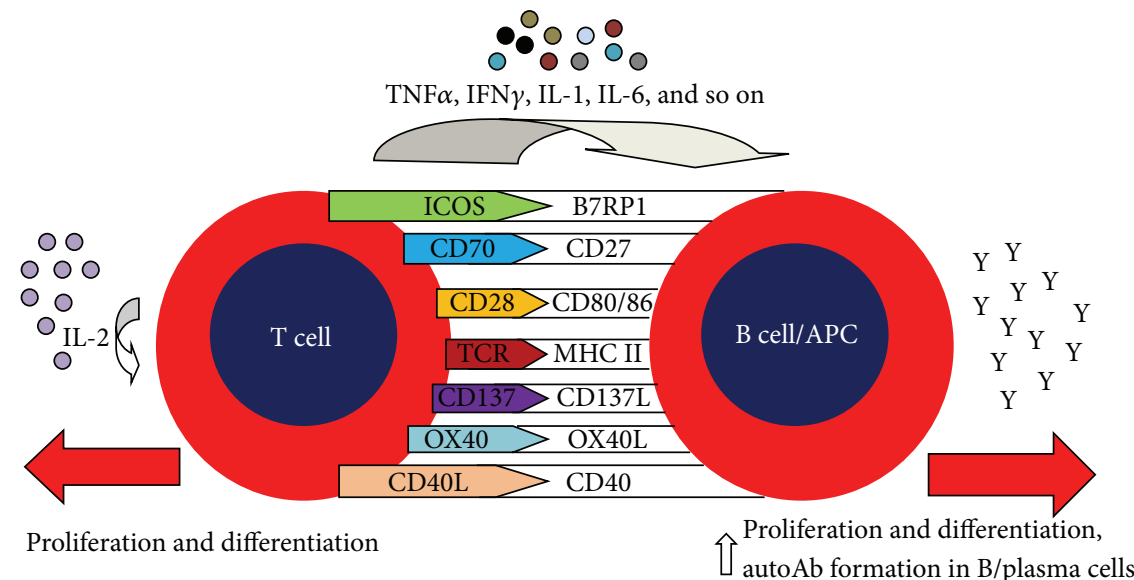

(b)

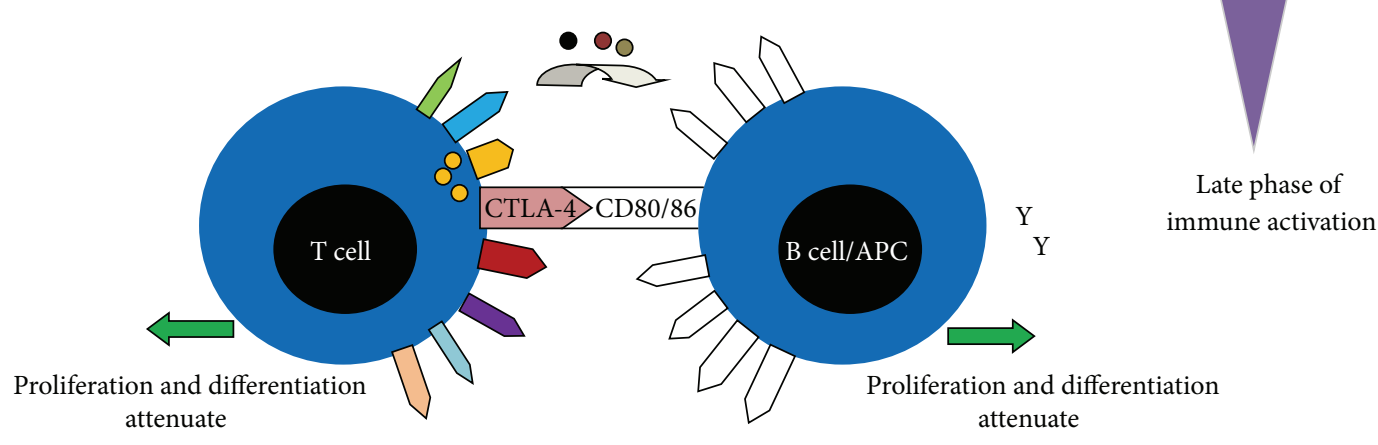

(c)

FIGURE 1: Expression of costimulation molecules in different stages of immune activation and their concerted effector functions. (a) Initial phase of immune activation; (b) maximal phase of immune activation with expression of many costimulatory molecules (figure is for depiction only, costimulation molecules may not be all expressed in a single immune reaction), coupled with proliferation and differentiation of immunocytes, production of proinflammatory cytokines and autoantibodies; (c) after reaching the peak of activation, CTLA4 expressed on T cells interacts with CD80/86 on B cells/APCs with higher affinity than CD28. Immune response attenuates and costimulatory pathways start to disintegrate. CD28 molecules expressed during maximal activation phase are endocytosed, pictorially depicted as intracellular small round yellow vesicles in the T cells of condition (c). Abbreviations: TCR: T-cell receptor; MHC II: class II major histocompatibility complex; APC: antigen-presenting cells; and autoAb: autoantibodies.

H4 acetylation levels) within the TNFSF7 promotor region [56].

High expressions of CD27 in B cells and plasma cells were shown to correlate with SLE disease activity in terms of higher SLEDAI, anti-dsDNA IgG levels, and lower serum complement levels in a cross-sectional study of 59 patients with SLE [57]. However, concurrent infection in these patients with elevated CD27 expression in their plasma cells limits the clinical utility of CD27+ plasma cell level as an ideal marker of lupus disease activity [57].

3.3. CD40-CD40L Interaction. The CD40L gene, similar to that of CD70, is methylation sensitive. The CD40L gene is a SLE susceptible gene located on the X chromosome. Partly as a consequence of demethylated regulatory sequence on the inactive $\mathrm{X}$ chromosome, $\mathrm{CD} 40 \mathrm{~L}$ was found to be 
overexpressed on $\mathrm{T}$ cells of female lupus patients $[58,59]$. $\mathrm{CD} 4+\mathrm{T}$ cells from female lupus patients treated in vitro with DNA methylation inhibitors were shown to overexpress CD40L mRNA, and elevation of CD40L expression has been unanimously shown to promote autoantibody production in B cells in the presence of their strong interaction with CD40 expressed on T cells $[58,59]$. Blocking the interaction between $\mathrm{CD} 40 \mathrm{~L}$ and $\mathrm{CD} 40$ is thus a feasible approach to ameliorate autoantibody production and hence the clinical manifestation of SLE [59]. In fact, CD40L blockade has been shown to prevent the development of SLE effectively in a lupus mouse model [60].

Clinical trials testing the blockade of the CD40-CD40L pathway in the treatment of SLE are disappointing [61, $62]$. In addition to the failure of meeting the predefined study end-points, the unfavourable side-effect profile of anti-CD40L (BG9588) led to premature termination of a multicentre phase II trial of BG9588 in SLE [62]. In a doubleblind, placebo-controlled, multiple-dose study, 85 patients with mild to moderately active SLE were randomized to receive 6 infusions of IDEC- 151 of $2.5,5$, and $10 \mathrm{mg} / \mathrm{kg}$ and placebo at $0,2,4,8,12$, and 16 weeks [61]. At 20 weeks, although the SLEDAI scores improved in all groups from baseline, statistical significance was not reached amongst the different groups. No difference in the predefined secondary outcomes including BILAG, physician and patient global assessment, Krupp fatigue assessment, serum anti-dsDNA and complement levels, and quality of life was noted. Adverse events were comparable between both groups, and none of the subjects developed anti-CD154 antibody after 16 weeks of treatment [61]. In another smaller phase II, open-label trial of evaluating anti-CD40L antibody (BG9588) in the treatment of 28 patients with proliferative lupus glomerulonephritis $(20 \mathrm{mg} / \mathrm{kg}$ biweekly for 3 doses then monthly for 4 additional doses), the occurrence of 2 myocardial infarctions 59 and 9 days after infusion, respectively, led to premature termination of the trial, even though patients on BG9588 treatment demonstrated significant reduction of proteinuria, haematuria, and anti-dsDNA titre with increase in serum C3 levels [62].

\subsection{CD137-CD137L Interaction. Although CD137 activation} upon ligation with CD137L provokes bidirectional signalling which induces proliferation and differentiation of both $\mathrm{T}$ and B cells, knocking out CD137 paradoxically induces more autoantibody production, higher level of pathogenic CD4+ and double negative $\mathrm{T}$ cells (CD3+CD4-CD8-B220+), more severe cutaneous lupus, glomerulonephritis, and death in the MRL/lpr mouse model [63]. The results led to the hypothesis that if CD137 is agonized, the opposite effects which favour amelioration of SLE might occur. Two separate studies using knockout mice of different backgrounds unanimously demonstrated amelioration of lupus phenotypically and serologically by agonizing CD137 receptor $[64,65]$. By injecting agonistic CD137 monoclonal antibody $(\mathrm{mAb})$, reduction in glomerulonephritis in MRL/lpr mice was demonstrated, besides reduction in CD4+ lymphocytes, anti-dsDNA production, germinal centre formation in secondary lymphoid organs, and mortality [65]. The same mAb injected into NZWB/W lupus-prone mice in another study produced similar results, except that no reduction of CD4+ was demonstrated [64]. Instead, an elevation of splenic CD25+ Treg cells was shown in the agonistic CD137 mAb group when compared with injection of isotype control [64]. Of particular note is that while agonizing CD137 has shown benefits in reducing the pathogenic autoantibodies and lymphocytes and amelioration of clinical manifestation of SLE in animal models, a number of in vitro studies using nonlupus human samples have revealed that CD137 activation enhances ingression of monocytes and their interaction with ICAM1 in blood vessels, leading to atherosclerosis and plaque inflammation which may potentially amplify cardiovascular risk [66-68].

3.5. OX40/OX40L. OX40 (CD134) expression in lupus PBMCs is predominantly restricted in $\mathrm{CD} 3+\mathrm{CD} 4+$ $\mathrm{CD} 45 \mathrm{RO}+\mathrm{T}$ lymphocytes, and the level correlates with lupus disease activity [69]. OX40 has also been found to be highly expressed in kidneys of patients with lupus nephritis [70]. While there have been no therapeutic trials performed in animals and humans addressing the safety and efficacy of blocking OX40-OX40L in the treatment of SLE, in vitro studies revealed that anti-CD134mAb-treated splenocytes of BXSB mice expressed significantly less markers of active SLE such as anti-dsDNA, IL-6, and IFN $\gamma$ [71]. In a small mechanistic study of 10 patients with SLE, stimulation of PBMCs under the influence of anti-CD134 $\mathrm{mAb}$ resulted in reduction of Th2 cytokine but increase in IFN $\gamma$ production [72]. Stimulation with CD134-Fc fusion protein further reduced the production of both Th1 and Th2 cytokines including IL-4, IL-10, and IFN $\gamma$ in patients with lupus nephritis [72], suggesting the potential role of anti-CD134 in reducing IL-4- and IL-10-mediated renal inflammation. In another study, expression of OX40 on IL-17-producing T cells was higher in SLE patients when compared with that of healthy controls [73]. Furthermore, expression of OX40 on $\mathrm{T}$ cells was correlated with lupus disease activity, and OX40+ $\mathrm{T}$ cells were found in renal biopsies of patients with lupus nephritis, which may signify that $\mathrm{OX} 40+\mathrm{T}$ cells migrate to the nephritic kidneys and contribute to inflammation and IL-17 production by interaction with CD137L-expressing resident renal cells [73]. Culture of lupus PBMCs with CD134 $\mathrm{mAb}$ in another experiment demonstrated inhibition of haemolytic activity and perforin expression on the PBMCs, and the degree of inhibition was associated with the disease activity of SLE and the degree of proteinuria [74].

3.6. ICOS-B7RP-1. Without interaction with B7RP1, ICOSdeficient mice were noted to have reduced total IgG and anti-dsDNA production [75]. In NZB/W F1 mouse model, blockade of B7RP1 with anti-B7h mAb before the onset of renal disease significantly delayed the onset of proteinuria, inhibited all subclasses of IgG autoantibody production, reduced the degree of glomerulonephritis, and prolonged the survival of the mice [76]. Even after the appearance of proteinuria in established disease, anti-B7h $\mathrm{mAb}$ consistently improved the renal histopathology and disease progression 
TABLE 2: Major translational studies and clinical trials testing various potential co-stimulatory molecules in the treatment of systemic lupus erythematosus.

\begin{tabular}{|c|c|c|c|}
\hline $\begin{array}{l}\text { Molecule } \\
\text { (ref.) }\end{array}$ & Nature & $\begin{array}{l}\text { In vitro/animal/observational studies in } \\
\text { humans }\end{array}$ & Clinical trial \\
\hline $\begin{array}{l}\text { CTLA-4Ig } \\
{[37-} \\
40,42,43,45]\end{array}$ & $\begin{array}{l}\text { Recombinant } \\
\text { fusion protein }\end{array}$ & $\begin{array}{l}\text { Reduces autoreactive B cells, autoantibodies, } \\
\text { IFN } \gamma \text { production, and class switching, along } \\
\text { with amelioration of GN in animal models } \\
\text { Dampens cognate interactions between T-B } \\
\text { cells and reduction in autoimmune-driven } \\
\text { inflammation }\end{array}$ & $\begin{array}{l}\text { No statistically significant difference in new } \\
\text { BILAG A or B flares in a RCT of } 175 \text { patients. If } \\
\text { only BILAG A was assessed in post hoc } \\
\text { analyses, more patients on placebo flared than } \\
\text { those received Tx ( } 54.4 \% \text { versus } 40.7 \% \text { ). More } \\
\text { adverse events were noted in placebo than Tx } \\
\text { group (19.8\% versus } 6.8 \% \text { ) } \\
\text { In another RCT of } 290 \text { patients with class III or } \\
\text { IV lupus nephritis, no significant difference was } \\
\text { found between both Tx and placebo groups in } \\
\text { complete renal response. Using the ALMS and } \\
\text { LUNAR response criteria in post hoc analyses, } \\
\text { more patients on the Tx group than those on } \\
\text { placebo had complete renal response } \\
\text { The ACCESS trial is currently underway }\end{array}$ \\
\hline
\end{tabular}

No change in $L \phi$ count and phenotypes in

NZB/W F1 mice was noted. Drives

Anti-ICOS

$\mathrm{Ab}[76]$

$\mathrm{mAb}$

production of IFN $\gamma \&$ Th 2 cytokine and apoptosis upon T-cell stimulation with OVA

Nil

in SCID mice. In humans, ICOS expression is

elevated in CD4+ and CD8+ T cells

Anti-

B7RP1/anti-

B7h Ab

$\mathrm{mAb}$

$[76,78]$
Delays the onset of proteinuria, inhibits IgG production, reduces $\mathrm{GN}$, and prolongs survival in NZB/W F1 mice. Improves renal histology and disease progression in NZB/W F1 mice with established disease
Agonistic to CD137, leading to reduction of GN, splenic CD4+ T cells, anti-dsDNA production, germinal center formation, and reduced mortality in MRL/lpr mice. In NZW/B F1

Anti$\mathrm{CD} 137 \mathrm{Ab}$

$\mathrm{mAb}$ $[64,65]$ reduction in splenic $\mathrm{CD} 4+$ count but mice, similar effect as in MRL/lpr mice yet no elevation of splenic CD25+ Treg cells In nonlupus human samples, CD137 agonization induces vascular inflammation, plaque formation, and atherosclerosis

Reduces Th1 and Th2 cytokine and IFN $\gamma$ production from PBMCs in patients with lupus nephritis

Recombinant
fusion protein [72]

Anti-

CD134Ab

$[71,72]$

$\mathrm{mAb}$

Reduces IL6, anti-dsDNA and IFN $\gamma$ levels in CD134mAb-treated splenocytes of BXSB mice Reduces Th 2 but increases IFN $\gamma$ production in PBMCs of patients with SLE

[71,72]

Phase $1 \mathrm{~b}$ trial (AMG557) for the treatment of stable lupus has just been completed. Data are being awaited 
in the animals [76]. Interestingly, in contrast to anti-B7h $\mathrm{mAb}$ treatment, anti-ICOS $\mathrm{mAb}$ treatment did not affect lymphocyte count and phenotypes of the animals. Instead, anti-ICOS $\mathrm{mAb}$ treatment of mice with severe combined immunodeficiency induced antigen-specific T-cell activation which led to the production of large amount of IFN $\gamma$ and Th2 cytokines, more apoptosis, and cell death [76]. Based on these observations, monoclonal antibodies against ICOS functionally trigger ICOS signalling instead of inhibiting it. The timing and immunological milieu when ICOS signalling is manipulated are postulated to be crucial in determining the effect of ICOS blockade. For example, delayed but not early, ICOS blockade of a mouse cardiac allograft model was shown to enhance cardiac graft survival where CD28 costimulation was absent and while CD8+ T cells, CTLA-4, and the STAT- 6 pathway were functionally active [77].

In humans, ICOS expression on CD4 and CD8+ T cells has been shown to be elevated in lupus patients, while ICOSL (B7RP1) expression is downregulated in peripheral blood memory B cells after cognate interaction with ICOS+ T cells in coculture systems. In lupus kidney samples, it was found that ICOS+ T and B cells which infiltrated the kidneys were in close contact, suggesting that T-B interactions may also take place in peripheral tissues [12]. A phase Ib trial assessing antiB7RP1 mAb (AMG 557) in the treatment of stable lupus has just been completed, and results are eagerly awaited [78].

Table 2 summarizes the major translational studies and clinical trials manipulating various costimulatory pathways in the treatment of SLE.

\section{Conclusion}

Costimulatory pathways initiate and perpetuate proinflammatory processes by sustaining cognate interaction between activated T cells and APCs which is central to the pathogenic process of SLE. Equally important, costimulatory pathways are capable of attenuating the ensuing proinflammatory response which is overwhelmed, as exemplified by the interaction between CTLA-4 and CD80/86 and prolonged CD137 stimulation.

While most studies involving murine lupus models have concluded the superior efficacy and safety of costimulatory blockade in treating lupus, most clinical trials which evaluated costimulatory blockers in SLE to date, such as CD154 and CTLA-4Ig, did not meet the predefined therapeutic endpoints. Nevertheless, reanalyses of these clinical trial data with the use of less stringent clinical response criteria and post hoc analyses may still advocate superior therapeutic value of these costimulatory blockades in moderate and severe lupus manifestations. Based on what we have learnt from the lessons of failure, there are 2 concomitant directions which we should proceed for reevaluating promising pharmacological agents and exploring potential biologic therapies for SLE. First, more realistic study design for clinical trials with less stringent and more practical endpoints can be employed to restudy medications such as abatacept and anti-CD154 $\mathrm{mAb}$. Second, a number of existing background treatments of SLE such as glucocorticoids and cyclophosphamide would obscure the potential therapeutic effects of the biologics being evaluated in clinical trials. As such, more thorough understanding of the molecular aspects of the existing treatments and their potential impact on the signalling mechanisms of the medications under evaluation will be beneficial. While the current data from clinical trials testing the efficacy and safety of anti-CD154 and CTLA-4Ig for the treatment of SLE have not been promising, novel yet potentially safer targets based on our current knowledge need to be explored. For example, instead of targeting CD137, antagonizing CD137L may be of potential to reduce disease severity and cardiovascular complications because agonizing CD137 may induce atherosclerosis which is potentially detrimental to patients with SLE [66-68]. Similarly, antagonizing B7RP1 may be safer because targeting at ICOS may actually stimulate it and potentially triggers more severe autoimmunity [76].

\section{References}

[1] A. Mak, D. A. Isenberg, and C. S. Lau, "Global trends, potential mechanisms and early detection of organ damage in SLE," Nature Reviews Rheumatology, vol. 9, no. 5, pp. 301-310, 2013.

[2] K. Tenbrock, Y.-T. Juang, V. C. Kyttaris, and G. C. Tsokos, "Altered signal transduction in SLE T cells," Rheumatology, vol. 46, no. 10, pp. 1525-1530, 2007.

[3] S. M. Fu, U. S. Deshmukh, and F. Gaskin, "Pathogenesis of systemic lupus erythematosus revisited 2011: end organ resistance to damage, autoantibody initiation and diversification, and HLA-DR," Journal of Autoimmunity, vol. 37, no. 2, pp. 104112, 2011.

[4] D. Male, J. Brostoff, R. B. Roth, and I. Roitt, "Immunology," in Antigen Presentation Immunology, pp. 145-162, Mosby Elsevier, Philadelphia, Pa, USA, 7th edition, 2006.

[5] D. Male, J. Brostoff, R. B. Roth, and I. Roitt, "Immunology," in Mechanisms of Innate Immunity, pp. 127-144, Mosby Elsevier, Philadelphia, Pa, USA, 7th edition, 2006.

[6] M. K. Crow, "Costimulatory molecules and T-cell-B-cell interactions," Rheumatic Disease Clinics of North America, vol. 30, no. 1, pp. 175-191, 2004.

[7] X. Tai, F. Van Laethem, L. Pobezinsky et al., "Basis of CTLA-4 function in regulatory and conventional CD4(+) T cells," Blood, vol. 119, no. 22, pp. 5155-5163, 2012.

[8] H. Bour-Jordan, J. H. Esensten, M. Martinez-Llordella, C. Penaranda, M. Stumpf, and J. A. Bluestone, "Intrinsic and extrinsic control of peripheral T-cell tolerance by costimulatory molecules of the CD28/B7 family," Immunological Reviews, vol. 241, no. 1, pp. 180-205, 2011.

[9] A. Aicher, M. Hayden-Ledbetter, W. A. Brady et al., "Characterization of human inducible costimulator ligand expression and function," Journal of Immunology, vol. 164, no. 9, pp. 4689-4696, 2000.

[10] S. Wang, G. Zhu, A. I. Chapoval et al., "Costimulation of T cells by B7-H2, a B7-like molecule that binds ICOS," Blood, vol. 96, no. 8, pp. 2808-2813, 2000.

[11] J. H. Ruth, J. B. Rottman, G. A. Kingsbury et al., "ICOS and B7 costimulatory molecule expression identifies activated cellular subsets in rheumatoid arthritis," Cytometry A, vol. 71, no. 5, pp. 317-326, 2007.

[12] A. Hutloff, K. Büchner, K. Reiter et al., "Involvement of inducible costimulator in the exaggerated memory B cell and plasma 
cell generation in systemic lupus erythematosus," Arthritis and Rheumatism, vol. 50, no. 10, pp. 3211-3220, 2004.

[13] T. Sato, T. Kanai, M. Watanabe et al., "Hyperexpression of inducible costimulator and its contribution on lamina propria $\mathrm{T}$ cells in inflammatory bowel disease," Gastroenterology, vol. 126, no. 3, pp. 829-839, 2004.

[14] K. Warnatz, L. Bossaller, U. Salzer et al., "Human ICOS deficiency abrogates the germinal center reaction and provides a monogenic model for common variable immunodeficiency," Blood, vol. 107, no. 8, pp. 3045-3052, 2006.

[15] T. Kobata, K. Agematsu, J. Kameoka, S. F. Schlossman, and C. Morimoto, "CD27 is a signal-transducing molecule involved in CD45RA+ naive T cell costimulation," Journal of Immunology, vol. 153, no. 12, pp. 5422-5432, 1994.

[16] J. Denoeud and M. Moser, "Role of CD27/CD70 pathway of activation in immunity and tolerance," Journal of Leukocyte Biology, vol. 89, no. 2, pp. 195-203, 2011.

[17] R. Q. Hintzen, S. M. A. Lens, K. Lammers, H. Kuiper, M. P. Beckmann, and R. A. W. van Lier, "Engagement of CD27 with its ligand CD70 provides a second signal for T cell activation," Journal of Immunology, vol. 154, no. 6, pp. 2612-2623, 1995.

[18] K. Karmann, C. C. W. Hughes, J. Schechner, W. C. Fanslow, and J. S. Pober, "CD40 on human endothelial cells: inducibility by cytokines and functional regulation of adhesion molecule expression," Proceedings of the National Academy of Sciences of the United States of America, vol. 92, no. 10, pp. 4342-4346, 1995.

[19] A. J. McAdam, R. J. Greenwald, M. A. Levin et al., "Icos is critical for CD40-mediated antibody class switching," Nature, vol. 409, no. 6816, pp. 102-105, 2001.

[20] S. W. Van Gool, P. Vandenberghe, M. de Boer, and J. L. Ceuppens, "CD80, CD86 and CD40 provide accessory signals in a multiple-step T-Cell activation model," Immunological Reviews, no. 153 , pp. 47-83, 1996.

[21] C. G. Katsiari, S.-N. C. Liossis, A. M. Dimopoulos, D. V. Charalambopoulos, M. Mavrikakis, and P. P. Sfikakis, "CD40L overexpression on $\mathrm{T}$ cells and monocytes from patients with systemic lupus erythematosus is resistant to calcineurin inhibition," Lupus, vol. 11, no. 6, pp. 370-378, 2002.

[22] M.-F. Liu, S.-C. Chao, C.-R. Wang, and H.-Y. Lei, "Expression of CD40 and CD40 ligand among cell populations within rheumatoid synovial compartment," Autoimmunity, vol. 34, no. 2, pp. 107-113, 2001.

[23] A. Durandy and S. Kracker, "Immunoglobulin class-switch recombination deficiencies," Arthritis Research and Therapy, vol. 14, no. 4, p. 218, 2012.

[24] S.-J. Lee, L. Myers, G. Muralimohan et al., “4-1BB and OX40 dual costimulation synergistically stimulate primary specific CD8 T cells for robust effector function," Journal of Immunology, vol. 173, no. 5, pp. 3002-3012, 2004.

[25] I. Melero, J. V. Johnston, W. W. Shufford, R. S. Mittler, and L. Chen, "NK1.1 cells express 4-1BB (CDw137) costimulatory molecule and are required for tumor immunity elicited by anti4-1BB monoclonal antibodies," Cellular Immunology, vol. 190, no. 2, pp. 167-172, 1998.

[26] H. Schwarz, J. Valbracht, J. Tuckwell, J. Von Kempis, and M. Lotz, "ILA the human 4-1BB homologue, is inducible in lymphoid and other cell lineages," Blood, vol. 85, no. 4, pp. $1043-$ 1052, 1995.

[27] V. Y. Taraban, T. F. Rowley, L. O’Brien et al., "Expression and costimulatory effects of the TNF receptor superfamily members CD134 (OX40) and CD137 (4-1BB), and their role in the generation of anti-tumor immune responses," European Journal of Immunology, vol. 32, no. 12, pp. 3617-3627, 2002.

[28] S. Pauly, K. Broll, M. Wittmann, G. Giegerich, and H. Schwarz, "CD137 is expressed by follicular dendritic cells and costimulates B lymphocyte activation in germinal centers," Journal of Leukocyte Biology, vol. 72, no. 1, pp. 35-42, 2002.

[29] A. Al-Shamkhani, S. Mallett, M. H. Brown, W. James, and A. N. Barclay, "Affinity and kinetics of the interaction between soluble trimeric OX40 ligand, a member of the tumor necrosis factor superfamily, and its receptor OX40 on activated T cells," Journal of Biological Chemistry, vol. 272, no. 8, pp. 5275-5282, 1997.

[30] T. Brocker, A. Gulbranson-Judge, S. Flynn, M. Riedinger, C. Raykundalia, and P. Lane, "CD4 T cell traffic control: in vivo evidence that ligation of OX40 on CD4 T cells by OX40-ligand expressed on dendritic cells leads to the accumulation of CD4 T cells in B follicles," European Journal of Immunology, vol. 29, no. 5, pp. 1610-1616, 1999.

[31] O. D’Orlando, G. Gri, G. Cattaruzzi et al., "Outside inside signalling in CD40-mediated B cell activation," Journal of Biological Regulators \& Homeostatic Agents, vol. 21, no. 3-4, pp. 49-62, 2007.

[32] T. Ito, Y.-H. Wang, O. Duramad et al., "0X40 ligand shuts down IL-10-producing regulatory T cells," Proceedings of the National Academy of Sciences of the United States of America, vol. 103, no. 35, pp. 13138-13143, 2006.

[33] A. K. S. Salama and F. S. Hodi, "Cytotoxic T-lymphocyte-associated antigen-4," Clinical Cancer Research, vol. 17, no. 14, pp. 4622-4628, 2011.

[34] Z. Xu, V. Juan, A. Ivanov et al., "Affinity and cross-reactivity engineering of CTLA4-Ig to modulate T cell costimulation," Journal of Immunology, vol. 189, no. 9, pp. 4470-4477, 2012.

[35] T. Pentcheva-Hoang, J. G. Egen, K. Wojnoonski, and J. P. Allison, "B7-1 and B7-2 selectively recruit CTLA-4 and CD28 to the immunological synapse," Immunity, vol. 21, no. 3, pp. 401-413, 2004.

[36] F. Fallarino, P. E. Fields, and T. F. Gajewski, "B7-1 engagement of cytotoxic $\mathrm{T}$ lymphocyte antigen 4 inhibits $\mathrm{T}$ cell activation in the absence of CD28," Journal of Experimental Medicine, vol. 188, no. 1, pp. 205-210, 1998.

[37] B. K. Finck, P. S. Linsley, and D. Wofsy, "Treatment of murine lupus with CTLA4Ig," Science, vol. 265, no. 5176, pp. 1225-1227, 1994.

[38] D. I. Daikh, B. K. Finck, P. S. Linsley, D. Hollenbaugh, and D. Wofsy, "Long-term inhibition of murine lupus by brief simultaneous blockade of the B7/CD28 and CD40/gp39 costimulation pathways," Journal of Immunology, vol. 159, no. 7, pp. 3104-3108, 1997.

[39] M. Mihara, I. Tan, Y. Chuzhin et al., "CTLA4Ig inhibits T cell-dependent B-cell maturation in murine systemic lupus erythematosus," Journal of Clinical Investigation, vol. 106, no. 1, pp. 91-101, 2000.

[40] A. Davidson, B. Diamond, D. Wofsy, and D. Daikh, "Block and tackle: CTLA4Ig takes on lupus," Lupus, vol. 14, no. 3, pp. 197203, 2005.

[41] P. G. Conaghan, P. Durez, R. E. Alten et al., "Impact of intravenous abatacept on synovitis, osteitis and structural damage in patients with rheumatoid arthritis and an inadequate response to methotrexate: the ASSET randomised controlled trial," Annals of the Rheumatic Diseases, vol. 72, no. 8, pp. 12871294, 2013. 
[42] J. T. Merrill, R. Burgos-Vargas, R. Westhovens et al., "The efficacy and safety of abatacept in patients with non-lifethreatening manifestations of systemic lupus erythematosus: results of a twelve-month, multicenter, exploratory, phase IIb, randomized, double-blind, placebo-controlled trial," Arthritis and Rheumatism, vol. 62, no. 10, pp. 3077-3087, 2010.

[43] R. Furie, K. Nicholls, T. T. Cheng et al., "Efficacy and safety of abatacept over 12 months in patients with lupus nephritis: results from a multicenter, randomized, double-blind, placebocontrolled phase II/III study," Arthritis and Rheumatism, vol. 63, pp. S962-S963, 2011.

[44] D. Wofsy, J. L. Hillson, and B. Diamond, "Abatacept for lupus nephritis: alternative definitions of complete response support conflicting conclusions," Arthritis and Rheumatism, vol. 64, no. 11, pp. 3660-3665, 2012.

[45] NCT00774852, http://www.clinicaltrial.gov/.

[46] Q. Shi, Z. Y. Gao, F. Xie et al., "A novel monoclonal antibody against human CD80 and its immune protection in a mouse lupus-like disease," International Journal of Immunopathology and Pharmacology, vol. 24, no. 3, pp. 583-593, 2011.

[47] R. Jaenisch and A. Bird, "Epigenetic regulation of gene expression: How the genome integrates intrinsic and environmental signals," Nature Genetics, vol. 33, pp. 245-254, 2003.

[48] B. Richardson, L. Scheinbart, J. Strahler, L. Gross, S. Hanash, and M. Johnson, "Evidence for impaired T cell DNA methylation in systemic lupus erythematosus and rheumatoid arthritis," Arthritis and Rheumatism, vol. 33, no. 11, pp. 1665-1673, 1990.

[49] A. Corvetta, R. D. Bitta, M. M. Luchetti, and G. Pomponio, "5Methylcytosine content of DNA in bloods, synovial mononuclear cells and synovial tissue from patients affected by autoimmune rheumatic diseases," Journal of Chromatography, vol. 566, no. 2, pp. 481-491, 1991.

[50] A. H. Sawalha and M. Jeffries, "Defective DNA methylation and CD70 overexpression in CD4+ T cells in MRL/lpr lupus-prone mice," European Journal of Immunology, vol. 37, no. 5, pp. 14071413, 2007.

[51] A. Kozlowska, P. Hrycaj, J. K. Lacki, and P. P. Jagodzinski, "Fyn and CD70 expression in CD4+ T cells from patients with systemic lupus erythematosus," Journal of Rheumatology, vol. 37, no. 1, pp. 53-59, 2010.

[52] K. Oelke, Q. Lu, D. Richardson et al., "Overexpression of CD70 and overstimulation of IgG synthesis by lupus $\mathrm{T}$ cells and $\mathrm{T}$ cells treated with DNA methylation inhibitors," Arthritis and Rheumatism, vol. 50, no. 6, pp. 1850-1860, 2004.

[53] B. K. Han, A. M. White, K. H. Dao, D. R. Karp, E. K. Wakeland, and L. S. Davis, "Increased prevalence of activated CD70+CD4+ T cells in the periphery of patients with systemic lupus erythematosus," Lupus, vol. 14, no. 8, pp. 598-606, 2005.

[54] Q. Lu, A. Wu, and B. C. Richardson, "Demethylation of the same promoter sequence increases CD70 expression in lupus $\mathrm{T}$ cells and T cells treated with lupus-inducing drugs," Journal of Immunology, vol. 174, no. 10, pp. 6212-6219, 2005.

[55] M. Zhao, Y. Sun, F. Gao et al., "Epigenetics and SLE: RFX1 downregulation causes CD1la and CD70 overexpression by altering epigenetic modifications in lupus CD4+ T cells," Journal of Autoimmunity, vol. 35, no. 1, pp. 58-69, 2010.

[56] Y. Zhou, X. Qiu, Y. Luo et al., "Histone modifications and methyl-CpG-binding domain protein levels at the TNFSF7 (CD70) promoter in SLE CD4+ T cells," Lupus, vol. 20, no. 13, pp. 13651371, 2011

[57] D.-H. Yang, D.-M. Chang, J.-H. Lai, F.-H. Lin, and C.-H. Chen, "Significantly higher percentage of circulating CD27high plasma cells in systemic lupus erythematosus patients with infection than with disease Flare-Up," Yonsei Medical Journal, vol. 51, no. 6, pp. 924-931, 2010.

[58] Q. Lu, A. Wu, L. Tesmer, D. Ray, N. Yousif, and B. Richardson, "Demethylation of CD40LG on the inactive X in T cells from women with lupus," Journal of Immunology, vol. 179, no. 9, pp. 6352-6358, 2007.

[59] Y. Zhou, J. Yuan, Y. Pan et al., "T cell CD40LG gene expression and the production of IgG by autologous B cells in systemic lupus erythematosus," Clinical Immunology, vol. 132, no. 3, pp. 362-370, 2009.

[60] G. S. Early, W. Zhao, and C. M. Burns, "Anti-CD40 ligand antibody treatment prevents the development of lupus-like nephritis in a subset of New Zealand black x New Zealand white mice. Response correlates with the absence of an anti-antibody response," Journal of Immunology, vol. 157, no. 7, pp. 3159-3164, 1996.

[61] K. C. Kalunian, J. C. Davis Jr., J. T. Merrill, M. C. Totoritis, D. Wofsy, and IDEC-131 Lupus Study Group, "Treatment of systemic lupus erythematosus by inhibition of $\mathrm{T}$ cell costimulation with anti-CD154: A randomized, double-blind, placebocontrolled trial," Arthritis and Rheumatism, vol. 46, no. 12, pp. 3251-3258, 2002.

[62] D. T. Boumpas, R. Furie, S. Manzi et al., "A short course of BG9588 (anti-CD40 ligand antibody) improves serologic activity and decreases hematuria in patients with proliferative lupus glomerulonephritis," Arthritis and Rheumatism, vol. 48, no. 3, pp. 719-727, 2003.

[63] D. S. Vinay, J. H. Choi, J. D. Kim, B. K. Choi, and B. S. Kwon, "Role of endogenous 4-1BB in the development of systemic lupus erythematosus," Immunology, vol. 122, no. 3, pp. 394-400, 2007.

[64] J. Foell, S. Strahotin, S. P. O’Neil et al., "CD137 costimulatory T cell receptor engagement reverses acute disease in lupus-prone NZB $\times$ NZW F1 mice," Journal of Clinical Investigation, vol. 111, no. 10, pp. 1505-1518, 2003.

[65] Y. Sun, H. M. Chen, S. K. Subudhi et al., "Costimulatory molecule-targeted antibody therapy of a spontaneous autoimmune disease," Nature Medicine, vol. 8, no. 12, pp. 1405-1413, 2002.

[66] P. S. Olofsson, L. Å. Söderström, D. Wågsäter et al., “CD137 is expressed in human atherosclerosis and promotes development of plaque inflammation in hypercholesterolemic mice," Circulation, vol. 117, no. 10, pp. 1292-1301, 2008.

[67] D. Drenkard, F. M. Becke, J. Langstein et al., "CD137 is expressed on blood vessel walls at sites of inflammation and enhances monocyte migratory activity," The FASEB Journal, vol. 21, no. 2, pp. 456-463, 2007.

[68] B. Z. Quek, Y. C. Lim, J. H. R. Lin et al., "CD137 enhances monocyte-ICAM-1 interactions in an E-selectin-dependent manner under flow conditions," Molecular Immunology, vol. 47, no. 9, pp. 1839-1847, 2010.

[69] S. Patschan, S. Dolff, A. Kribben et al., "CD134 expression on $\mathrm{CD} 4+\mathrm{T}$ cells is associated with nephritis and disease activity in patients with systemic lupus erythematosus," Clinical \& Experimental Immunology, vol. 145, no. 2, pp. 235-242, 2006.

[70] J. Aten, A. Roos, N. Claessen, E. J. M. Schilder-Tol, I. J. M. Ten Berge, and J. J. Weening, "Strong and selective glomerular localization of CD134 ligand and TNF receptor-1 in proliferative lupus nephritis," Journal of the American Society of Nephrology, vol. 11, no. 8, pp. 1426-1438, 2000. 
[71] Y.-B. Zhou, R.-G. Ye, Y.-J. Li, C.-M. Xie, and Y.-H. Wu, "Effect of anti-CD134L mAb and CTLA4Ig on ConA-induced proliferation, Th cytokine secretion, and anti-dsDNA antibody production in spleen cells from lupus-prone BXSB mice," Autoimmunity, vol. 41, no. 5, pp. 395-404, 2008.

[72] Y.-B. Zhou, R.-G. Ye, Y.-J. Li, and C.-M. Xie, "Targeting the CD134-CD134L interaction using anti-CD134 and/or rhCD134 fusion protein as a possible strategy to prevent lupus nephritis," Rheumatology International, vol. 29, no. 4, pp. 417-425, 2009.

[73] S. Dolff, D. Quandt, B. Wilde et al., "Increased expression of costimulatory markers CD134 and CD80 on interleukin-17 producing T cells in patients with systemic lupus erythematosus," Arthritis Research \& Therapy, vol. 12, no. 4, article R150, 2010.

[74] M. Li, Q. Yang, and Y. Zhang, "Effects of CD134 monoclonal antibody on hemolysis activities and expression of perforin in peripheral blood mononuclear cells of systemic lupus erythematosus patients," Hybridoma, vol. 26, no. 4, pp. 191-200, 2007.

[75] Y. Tada, S. Koarada, Y. Tomiyoshi et al., "Role of inducible costimulator in the development of lupus in MRL/lpr mice," Clinical Immunology, vol. 120, no. 2, pp. 179-188, 2006.

[76] H. Iwai, M. Abe, S. Hirose et al., "Involvement of inducible costimulator-B7 homologous protein costimulatory pathway in murine lupus nephritis," Journal of Immunology, vol. 171, no. 6, pp. 2848-2854, 2003.

[77] H. Harada, A. D. Salama, M. Sho et al., "The role of the ICOSB7h T cell costimulatory pathway in transplantation immunity," Journal of Clinical Investigation, vol. 112, no. 2, pp. 234-243, 2003.

[78] NCT00774943, http://www.clinicaltrial.gov/.

[79] C. E. Rudd, A. Taylor, and H. Schneider, "CD28 and CTLA-4 coreceptor expression and signal transduction," Immunological Reviews, vol. 229, no. 1, pp. 12-26, 2009.

[80] M.-L. Alegre, K. A. Frauwirth, and C. B. Thompson, "T-cell regulation by CD28 and CTLA-4," Nature Reviews Immunology, vol. 1, no. 3, pp. 220-228, 2001.

[81] S. Karakhanova, S. Meisel, S. Ring, K. Mahnke, and A. H. Enk, "ERK/p38 MAP-kinases and PI3K are involved in the differential regulation of B7-H1 expression in DC subsets," European Journal of Immunology, vol. 40, no. 1, pp. 254-266, 2010.

[82] Q. Tang, D. Jiang, Z. Shao, J. M. Martinez Gomez, and H. Schwarz, "Species difference of CD137 ligand signaling in human and murine monocytes," PLoS ONE, vol. 6, no. 1, Article ID e16129, 2011.

[83] M. C. Moh, P. A. Lorenzini, C. Gullo, and H. Schwarz, “Tumor necrosis factor receptor 1 associates with CD137 ligand and mediates its reverse signaling," The FASEB Journal, 2013.

[84] J. Borst, J. Hendriks, and Y. Xiao, "CD27 and CD70 in T cell and B cell activation," Current Opinion in Immunology, vol. 17, no. 3 , pp. 275-281, 2005.

[85] M. Croft, "Control of Immunity by the TNFR-related molecule OX40 (CD134)," Annual Review of Immunology, vol. 28, pp. 5778, 2010.

[86] M. J. Gough and A. D. Weinberg, "OX40 (CD134) and OX40L," Advances in Experimental Medicine and Biology, vol. 647, pp. 94-107, 2009.

[87] R. Elgueta, M. J. Benson, V. C. de Vries, A. Wasiuk, Y. Guo, and R. J. Noelle, "Molecular mechanism and function of CD40/CD40L engagement in the immune system," Immunological Reviews, vol. 229, no. 1, pp. 152-172, 2009. 


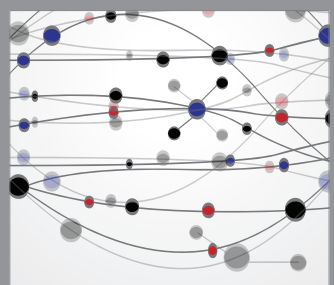

The Scientific World Journal
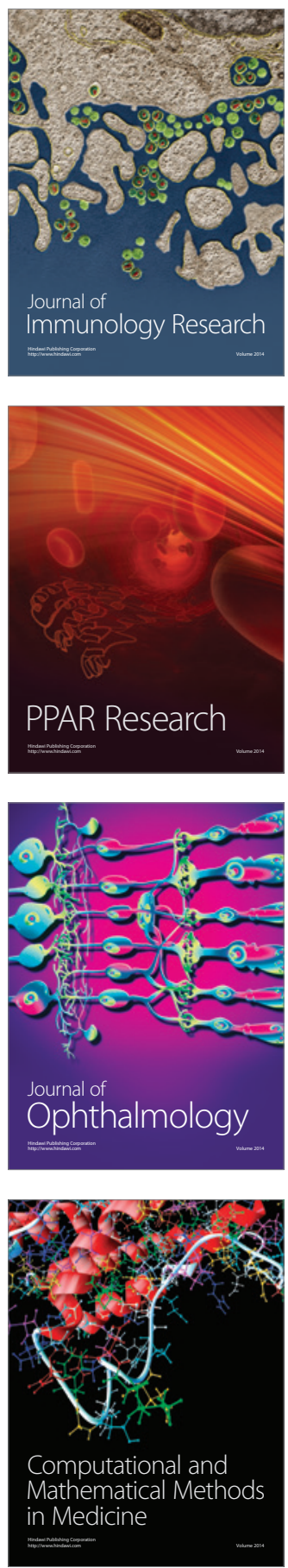

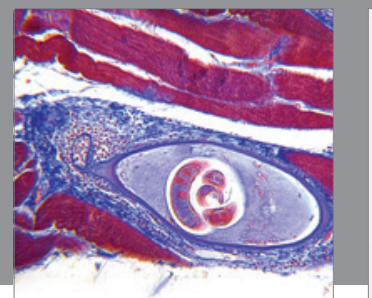

Gastroenterology

Research and Practice
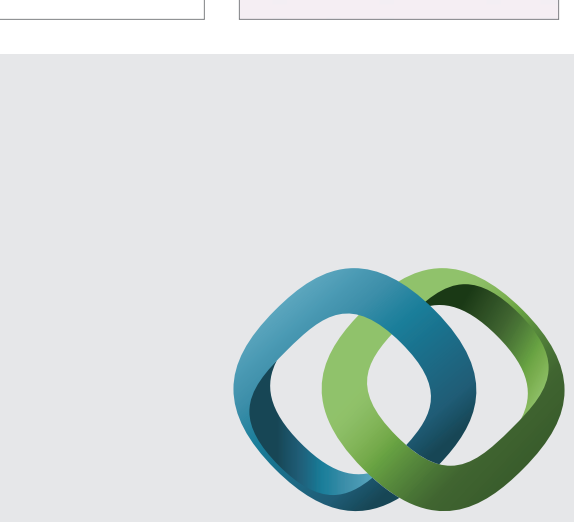

\section{Hindawi}

Submit your manuscripts at

http://www.hindawi.com
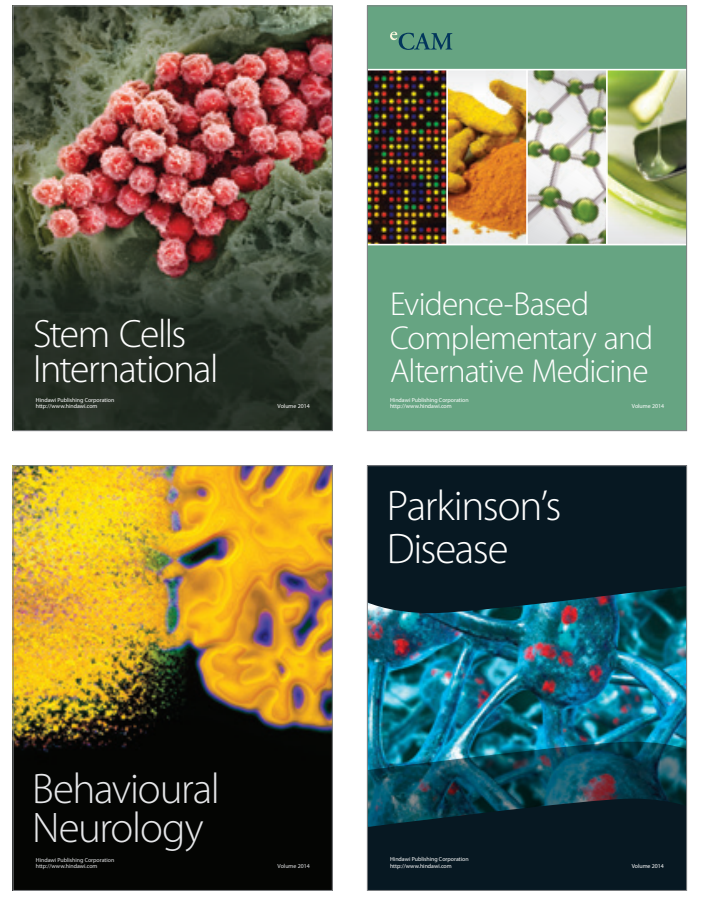
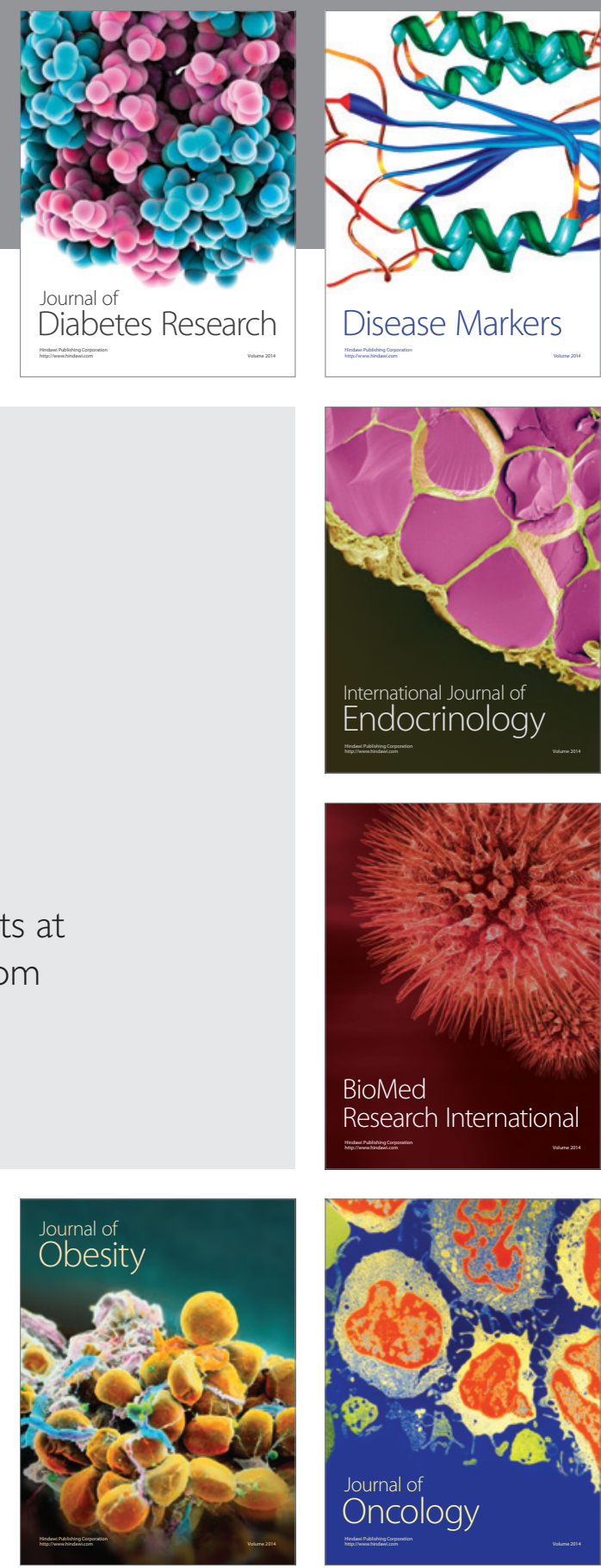

Disease Markers
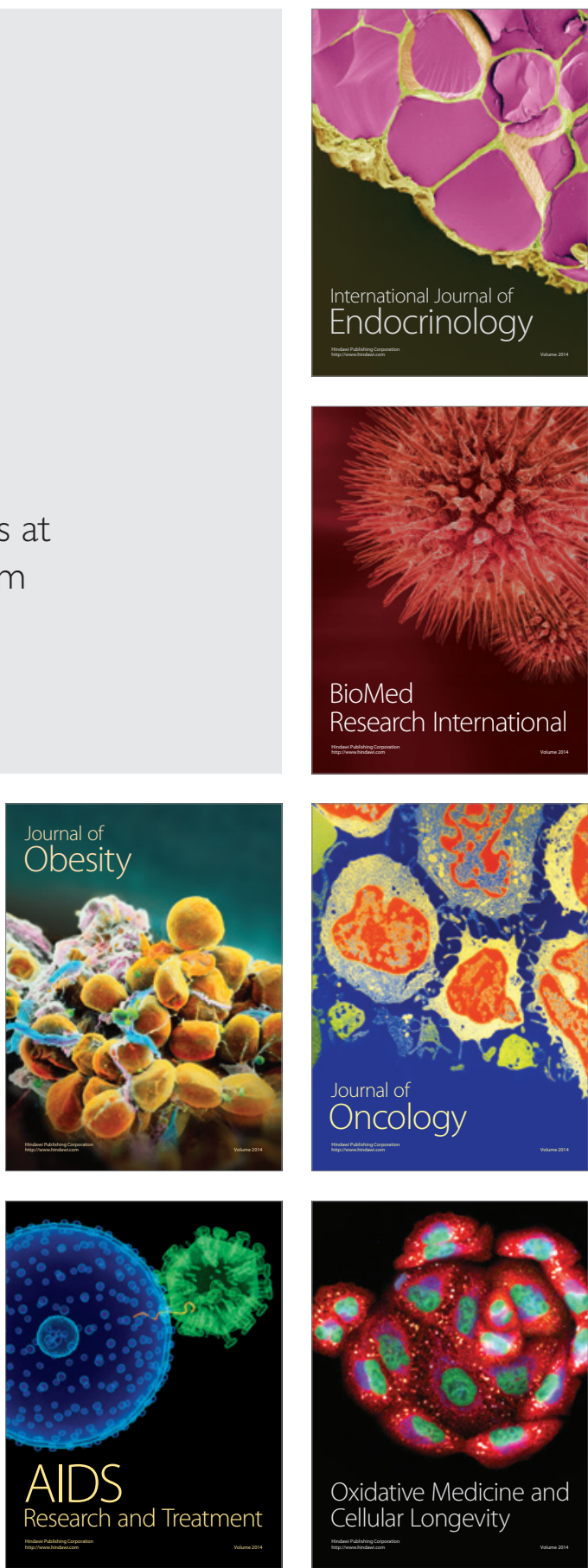